\title{
COVID-19 India Tracker Application using Flutter
}

\author{
Sanju Kumar Sahu ${ }^{1}$ | M.L. Sharma ${ }^{1} \mid$ Krishna Chandra Tripathi ${ }^{1}$ \\ ${ }^{1}$ Information Technology, Maharaja Agrasen Institute of Technology, Rohini, Delhi \\ To Cite this Article \\ Sanju Kumar Sahu, M.L. Sharma and Krishna Chandra Tripathi, "COVID-19 India Tracker Application using Flutter", \\ International Journal for Modern Trends in Science and Technology, Vol. 07, Issue 01, January 2021, pp.-10-15.
}

\section{Article Info}

Received on 22-November-2020, Revised on 18-December-2020, Accepted on 22-December-2020, Published on 28-December-2020.

\section{ABSTRACT}

Nowadays, COVID-19 is the biggest impediment for the survival of the human race. Again, as mobile technology is now an important component of human life, hence it is possible to use the power of mobile technology against the treat of COVID-19.

Every nation is now trying to deploy an interactive platform for creating public awareness and share the important information related to COVID-19. Keeping all of these in mind, authors have deployed an interactive cross-platform (web/mobile) application INDIA COVID-19 TRACKER for the ease of the users, especially in India.

This dashboard is featured with all the real-time attributes about the novel coronavirus disease and its measures and controls. The system purposely aims to maintain the digital protection of the society, create public awareness, and not create any agitation situation among the individuals of the society.

KEYWORDS:flutter, COVID-19, mobile application.

\section{INTRODUCTION}

In Wuhan city of China, due to some unknown causes a local outbreak of pneumonia was notice in December 2019. originally, the disease got named serious acute respiratory syndrome coronavirus 2 (SARS-COV-2). Corona Virus Disease 19 (COVID-19) caused by the novel coronavirus is confirmed officially later by the World Health Organization and they also declare COVID-19 as the Public Health Emergency of International Concern (PHEIC). This ongoing outbreak of pneumonia spread rapidly all over the globe, causing more than $1,83,820$ deaths soon got identified as the cause of the novel coronavirus. As of April 25, 2020, more than 22,398 confirmed COVID-19 cases found in INDIA. Since then, no medicine is invented, which could cure the disease caused by the deadly virus, and social distancing was found to be a promising way to saturate the growth of the disease. Thus, most of the nations declared lockdown of the entire state to set a bar on the growing numbers of the disease. But it was found $42 \%$ of the society was not aware of the pandemic yet, and the lockdown caused a huge economic break.

Keeping all of these complex features in mind we have used all the promising technologies to build the mobile application as well as a web application. The speed and security are also enhanced by using decoupled cloud architecture for the entire system (i.e. separating the client-side cloud and the server-side cloud).. The dashboard is capable to report cases at the state level, city level and at the country level in INDIA. The COVID-19 related data published on the dashboard aligns with the WHO situation reports and the Ministry of Health and Family Welfare, Govt. of India for within and outside of INDIA, particularly. 
Nowadays, wireless communication in terms of mobile technology is an essential part of our life. This technology is now the guiding force for human life to perform any activities. Again, in this pandemic situation, fake news prevention and distribute genuine information, i.e., information regarding public awareness, test centers, geo-tracking, etc. to everyone in every time with minimum expense, it is perhaps the biggest challenge to any administration all over the world. Mobile technology is the only one stop solution for everything above mentioned problem.

\section{RELATED STUDIES}

In this pandemic condition, a couple of mobile applications are introduced by government institutions and others, which are providing valuable information to the people to aware of the pandemic situation, like the number of confirmed cases, number of recovered occasion, number of deaths as of now, etc. In this research, authors have restricted themselves from studying the mobile applications used now in India as our implemented app is showing useful information related to India. A brief review is presented here.

APOLLO, one of the biggest medical giants in India, developed a risk assessment scanner for COVID-19 outbreak in INDIA and named it "covid.apollo247". This risk assessment scanner comes with a tag line 'Stay calm amidst the current paranoia surrounding COVID-19' and is successful in reaching a major part of the society during this outbreak. The solution could efficiently predict the chances of risk (Low, Mid, High) of having positive coronavirus tress depending on multiple users given parameters using their ML algorithms.

A team of twenty plus members (teachers and students) from Mahindra Ecole Centrale developed a dashboard for smooth user experience and quality visualization of real-time data. The website shows the real-time data of the infected, cured, and deaths in INDIA, though some inconsistency is also observed in their application. Several graphs and charts are used in the website to visualize the data also at the district level, but more accuracy is expected concerning their results.

The Government of India took the initiative and developed a mobile application named AarogyaSetup to connect essential health services with the people of INDIA. Basically, it is a mobile application; still, the use of web views was found in the statistics display dashboard. They have also come up with a geo-tracking facility that helps the system to track the coronavirus affected people and form a cluster.

MICROSOFT BING is taken the novel attempt to implement a software solution for the COVID-19 pandemic across the world for data transparency and increasing traceability. Bing map comes with an interactive platform that focused on the world map. When hovering over the different countries, it used to render the COVID-19 statistics (Confirmed cases, Active cases, Deaths, Recovered) of the particular nation. In the web application of the Bing map, the statistics even at the district level of few countries like INDIA, as of 25th April 2020 is also shown.

\section{Methodology}

The system model of the developed system is shown in figure 1; authors have used a decoupled architecture for our designed interactive dashboard INDIA COVID-19. The entire model has divided into two major components the frontend and the backend. In the frontend, the user is provided with a cross-platform application (mobile/web), i.e., some Use Interface/User Experience (UI/UX), which requests data from the clientside cloud and displays the data to the user.

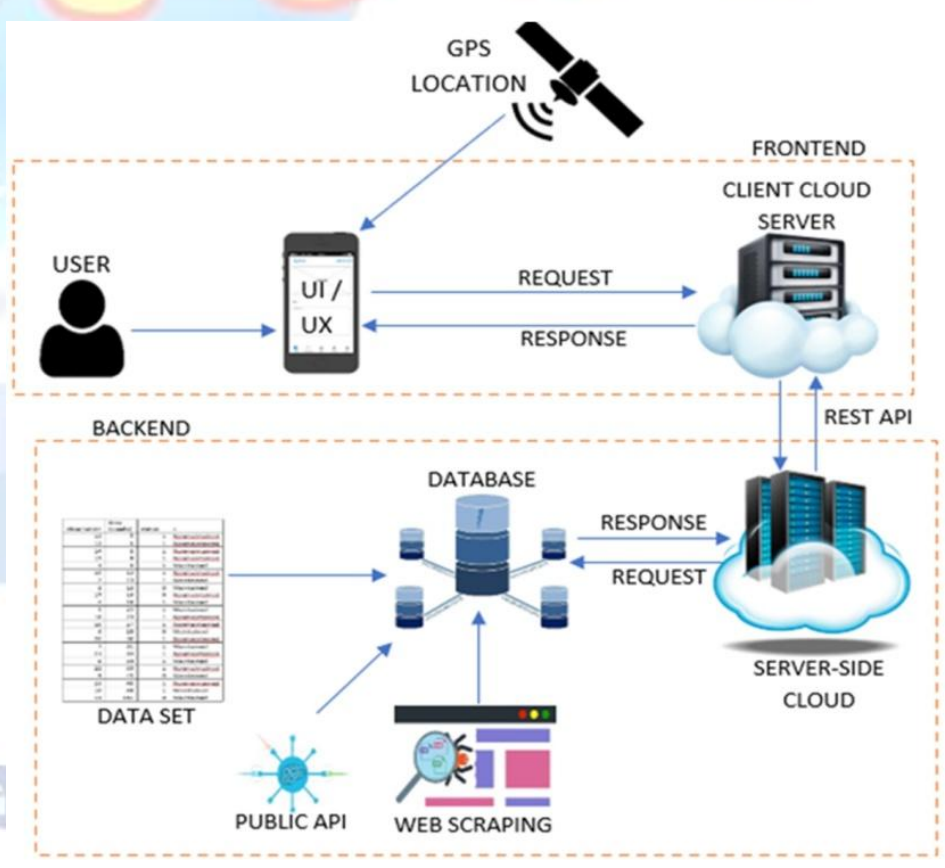

Figure. 1: Decoupled architecture of the developed cross-platform application (mobile/web)

Next comes the backend, which has a database and server-side cloud as its major components. The data from public API, web scraping, real-time datasets is fetched and stored in the database. The 
database and the server-side cloud also communicate in a similar response for request manner. In contrast, the data communication between the client-side cloud and the server-side cloud is maintained by our responsive REST API's. Thus, it makes the full system unique, helpful, secured, and user-friendly with all the features entitled to the users in an optimized way.

\section{DATABASE MODELING AND DESIGN:}

The proposed system is built on a cross-platform mobile application developed as a step towards making the general awareness of the people regarding the global pandemic due to COVID-19 on a nationwide scale. The Entity-Relationship Diagram (ERD) of the developed system is shown in figure 2 . The architecture of the proposed solution is a decentralized one where the frontend or the client-side logic is separated from the backend or the server-side logic.

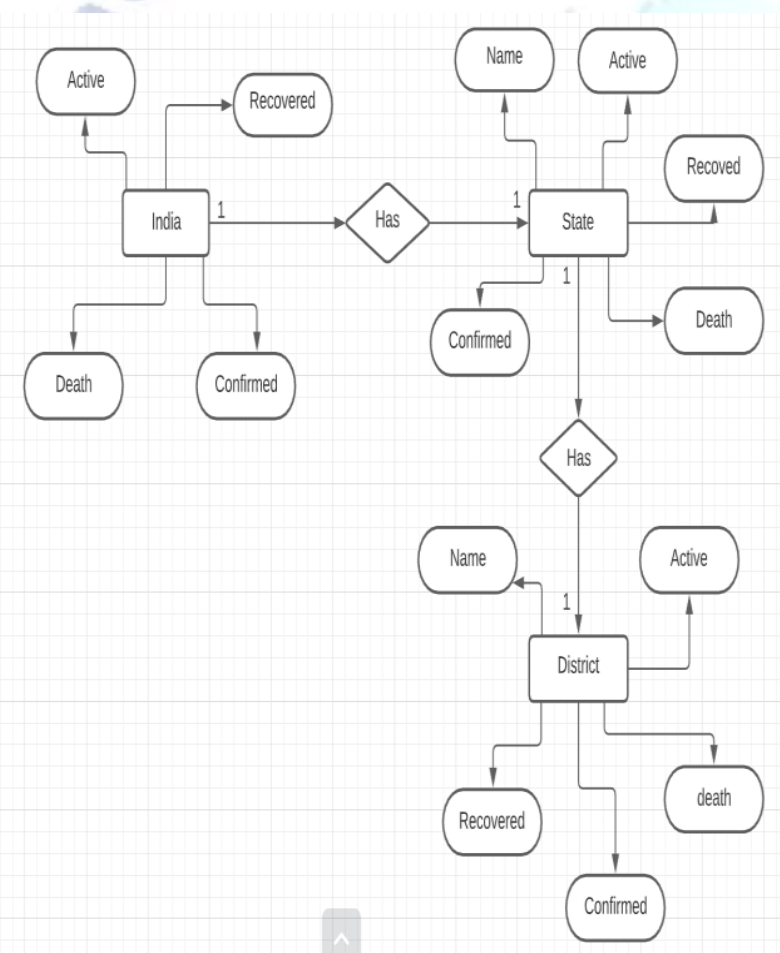

Figure. 2: An Entity-Relationship diagram of the proposed system

This approach allows the system to be more fast, efficient, and scalable. To connect the frontend with the backend, both deployed on two separate cloud computing platforms. The use of Representational State Transfer (R.E.S.T.) APIs plays a significant role in communicating between the client-side server and the database. In our proposed solution, the total number of active cases, confirmed cases, active cases, and deaths in the home page using the data provided from the backend database. We are also displaying nation-wide, state-wise and district-wise data of the number of confirmed cases with the use of geo graphs feature provided by Google Maps' API. With the use of chart.js, which is an open-source JavaScript charting library, we have created two other charts for better data representation. At first, we have implemented is a line chart with multiple axes denoting the number of confirmed cases, recovered cases, and the number of deaths. This approach allows the user, simple and easy access to the data in an understandable manner. All the necessary data is provided from the backend database.

\section{UML DIAGRAM OF THE DEVELOPED SYSTEM}

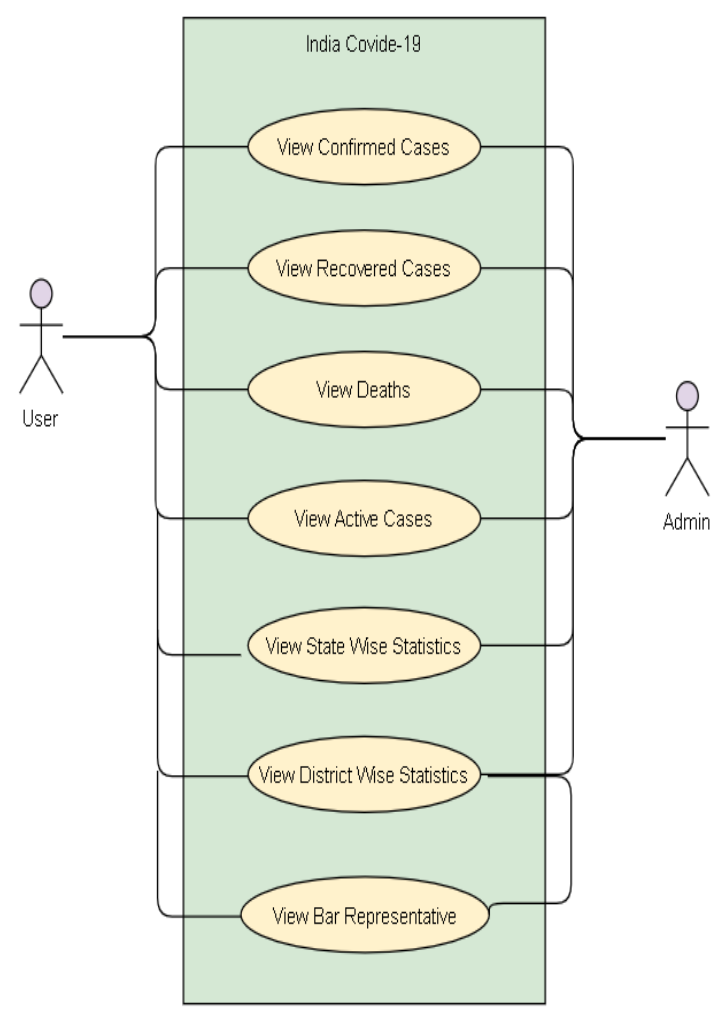

Figure. 3: UML Use-Case diagram of the developed system

In figure 3 , the UML use case diagram helps in defining the architecture of the developed application.

\section{FEATURES OF THE PROPOSED SOLUTION}

- Providing the total number of confirmed, active, recovered, and deaths on a national, state, and district level.

- Use of bar graph for better representation of confirmed, active, recovered, and death cases. 
- Able to predict health state based on the state's condition.

\section{COVID19 INDIA}

\section{RESULTS}

Comparative Study among Various Mobile Applications Currently Used in India to Combat COVID-19

In this section, prepared a comparative study in Table 1 among various mobile applications that are used in India to combat COVID-19 along with our implemented application. The table depicts that among all the mobile applications, our implemented application covers more features apart from world data.

Table 1: Comparative Study of various Mobile

\section{Applications}

\begin{tabular}{|l|l|l|l|l|l|l|l|l|}
\hline DS & $\begin{array}{l}\text { RI } \\
\text { D }\end{array}$ & $\begin{array}{l}\text { S } \\
\text { D }\end{array}$ & $\begin{array}{l}\text { D } \\
\text { D }\end{array}$ & $\begin{array}{l}\text { W } \\
\text { D }\end{array}$ & $\begin{array}{l}\text { TOR } \\
\text { I }\end{array}$ & $\begin{array}{l}\text { L } \\
\text { T }\end{array}$ & N & $\begin{array}{l}\text { WSG } \\
\text { R }\end{array}$ \\
\hline Apollo247 & $\mathrm{x}$ & $\mathrm{x}$ & $\mathrm{x}$ & $\mathrm{x}$ & $\sqrt{ }$ & $\mathrm{x}$ & $\mathrm{x}$ & $\mathrm{x}$ \\
\hline $\begin{array}{l}\text { Microsoft } \\
\text { Bing }\end{array}$ & $\sqrt{ }$ & $\mathrm{x}$ & $\mathrm{x}$ & $\sqrt{ }$ & $\mathrm{x}$ & $\mathrm{x}$ & $\sqrt{ }$ & $\mathrm{x}$ \\
\hline $\begin{array}{l}\text { AarogyaSet } \\
\mathrm{u}\end{array}$ & $\sqrt{ }$ & $\mathrm{x}$ & $\mathrm{x}$ & $\mathrm{x}$ & $\sqrt{ }$ & $\sqrt{ }$ & $\sqrt{ }$ & $\sqrt{ }$ \\
\hline $\begin{array}{l}\text { Covid-19 } \\
\text { Tracker }\end{array}$ & $\sqrt{ }$ & $\sqrt{ }$ & $\sqrt{ }$ & $\mathrm{x}$ & $\mathrm{x}$ & $\sqrt{ }$ & $\mathrm{x}$ & $\sqrt{ }$ \\
\hline
\end{tabular}

\section{DS = DEVELOPED SYSTEMS \\ RID $=$ REAL-TIME INFORMATIVE DATA \\ $\mathrm{SD}=$ STATE-WISE DATA \\ DD = DISTRICT-WISE DATA \\ $\mathrm{WD}=\mathrm{WORLD}$ DATA \\ TORI $=$ TEST ORIENTED RISK IDENTIFIER \\ LT $=$ LOCATION TRACKING \\ $\mathrm{N}=\mathrm{NEWS}$ \\ WSGR=WEEKLY STATUS GRAPHICALLY REPRESENTATION}

Figure 4 (a) select the location. figure(b) depicts the state-wise statistical data (death, active cases, confirmed cases, recovered) is shown on the bar chart. The user needs to hover on each state to view the real-time data of that state. This is implemented with the help of bar chart. The colour representation is provided for better understanding, i.e., lighter the colour indicates a smaller number of confirmed cases and vice-versa. Where, figure 4 (c) shows district-wise real-time statistical data (death, active cases, confirmed cases, recovered) of each state.
Select Your State

Select Your District
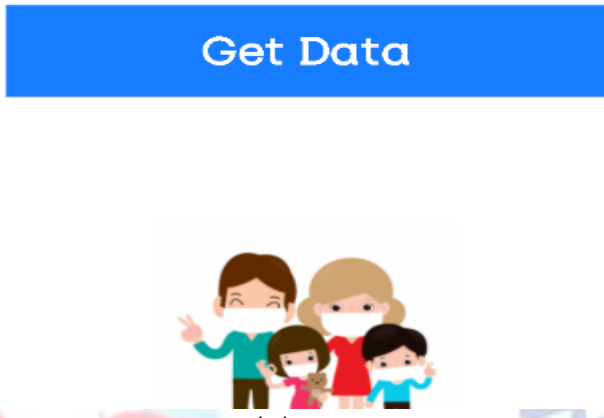

(a)

$\equiv$
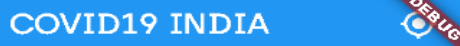

INDIA

Confirmed

$84,71,75$ 个 10,70

Activ

$5,18,213$

Recovered

$78,27,830 \uparrow 9,121$

Deceased

$1,25,71 \uparrow 108$

Tested

11 crore 65 lakh

Recovery Rate: 92.40

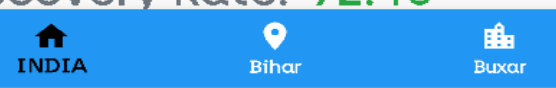

(b) 


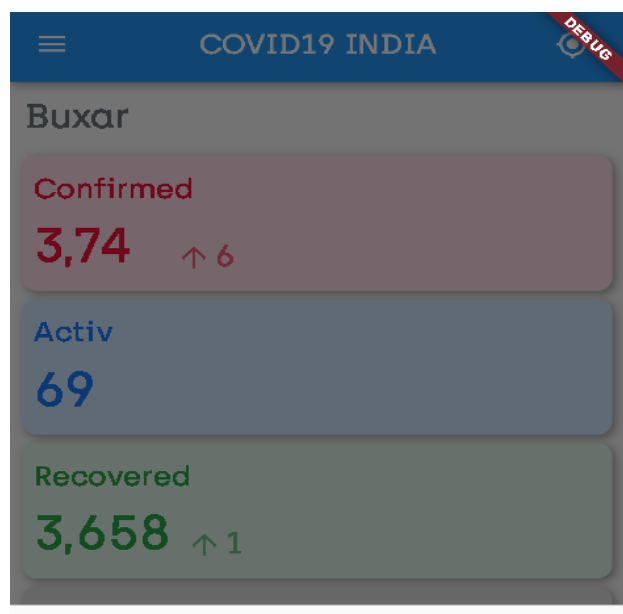

\section{Select Your State}

Select Your District

Get Data

(c)

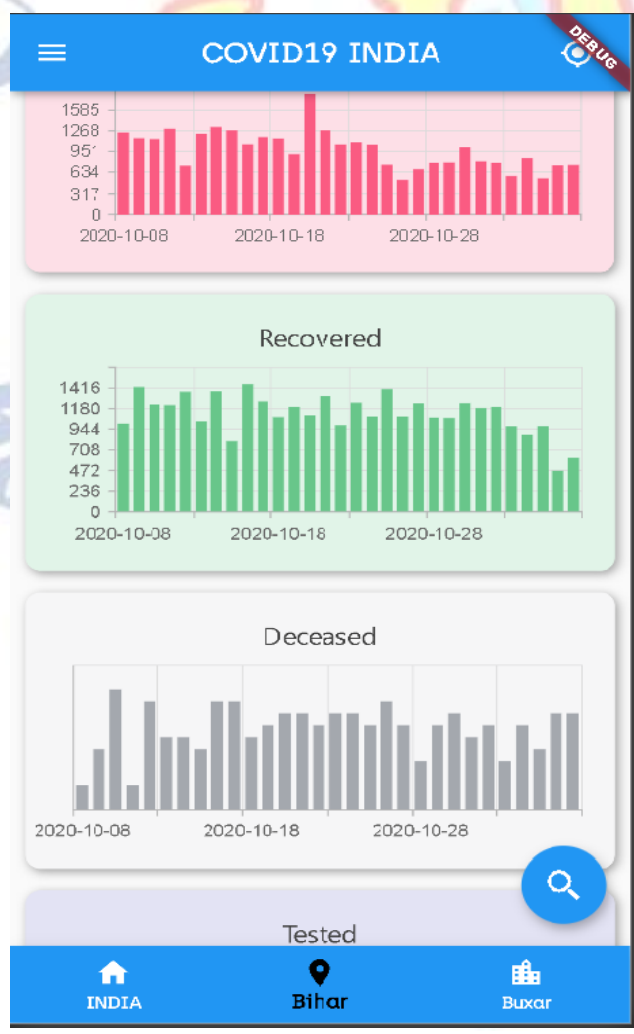

(d)

\section{DISCUSSION}

Proposed and implemented the mobile application INDIA COVID-19 with the aim in mind to make the society aware in maximum capacity about the current pandemic situation of the nation due to the COVID-19. With the help of technological advancement, we can provide critical information to the people in their mobile phones with the ease of accessing it wherever they want it. Considering the usefulness and impact of the dashboard, we are planning to extend this application further.We strongly believe that in the early stage, this application plays a pivotal role in controlling the diseases. Thus, the advanced technology-based mobile application performs a significant role to combat against COVID-19

\section{REFERENCES}

[1] Z. Y.Zu, M. D. Jiang, P. P. Xu, W. Chen, Q. Q. Ni, G. M. Lu, \& L. J. Zhang, “Coronavirus disease 2019 (COVID-19): a perspective from China”. Radiology, 200490, 2020

[2] W. Wang, J. Tang, \&F. Wei, "Updated understanding of the outbreak of 2019 novel coronavirus (2019-nCoV) in Wuhan, China". Journal of medical virology, 92(4), 441-447, 2020

[3] https://www.who.int/docs/defaultsource/coronavirus e/situation-reports / 20200307-sitrep-47-covid19.pdf?sf vrsn=27c364a4_2 (accessed March 7, 2020)

[4] WHO-China Joint Mission, Report of the WHO-China Joint Mission on Coronavirus Disease 2019 (COVID-19), (2020).

https://www.who.int/docs / default-source/coronavirus e/who-china-jointmission-on-covid-19-final-report.pdf (accessed March 1, 2020)

[5] J. S. Banerjee, and A. Chakraborty, "Fundamentals of Software Defined Radio and Cooperative Spectrum Sensing: A Step Ahead of Cognitive Radio Networks". In Handbook of Research on Software-Defined and Cognitive Radio Technologies for Dynamic Spectrum Management, IGI Global, pp 499-543 2015

[6] J.S. Banerjee, A. Chakraborty, and K. Karmakar, "Architecture of Cognitive Radio Networks". In N. Meghanathan\&Y.B.Reddy (Ed.), Cognitive Radio Technology Applications for Wireless and Mobile Ad Hoc Networks, IGI Global, pp 125-152 2013

[7] J. S. Banerjee, and A. Chakraborty, "Modeling of Software Defined Radio Architecture \& Cognitive Radio, the Next Generation Dynamic and Smart Spectrum Access Technology”. In M.H. Rehmani\& Y. Faheem (Ed.), Cognitive Radio Sensor Networks: Applications, Architectures, and Challenges, IGI Global, pp. 127-158 2014

[8] J. S. Banerjee, et. al., "A Comparative Study on Cognitive Radio Implementation Issues”, International Journal of Computer Applications, vol.45, no.15, pp. 44-51, May.2012

[9] J. S. Banerjee, A. Chakraborty, and A. Chattopadhyay, "A novel best relay selection protocol for cooperative cognitive radio systems using fuzzy AHP", Journal of Mechanics of Continua and Mathematical Sciences, 13(2), 72-87, 2018

[10] https://www.bing.com/covid

[11] S. Paul, A. Chakraborty, and J. S. Banerjee, "A Fuzzy AHP-Based Relay Node Selection Protocol for Wireless Body Area Networks (WBAN)", In: Proc. OPTRONIX 2017, IEEE, pp. 1-6, Nov. 2017

[12] S. Paul, A. Chakraborty, and J. S. Banerjee, "The Extent Analysis Based Fuzzy AHP Approach for Relay Selection 
in WBAN", In: Proc. CISC, (pp. 331-341). Springer, Singapore, 2019

[13] S. Guhathakurata, S. Kundu, A. Chakraborty, J. S.Banerjee, "A Novel Approach to Predict COVID-19 Using Support Vector Machine".In Data Science for COVID-19, Elsevier (press), 2020

[14] WHO-China Joint Mission, Report of the WHO-China Joint Mission on Coronavirus Disease 2019

[15] (COVID-19), (2020).

https://www.who.int/docs/default-source/coronavirus e/who-china-joint- mission-on-covid-19-final-report.pdf (accessed March 1, 2020)

[16] Apple Covid-19 (2020). [online] Available from: https://apps.apple.com/us/app/id1504132184 [Accessed 23 April 2020].

[17] Porter, J. (2020) Apple's Siri voice assistant now provides coronavirus advice. Available from: https://www.theverge.com/2020/3/23/21190600/app le-siricoronavirus-covid-19-symptoms-healthcare-advic e-information [Access 23 April 2020].

[18] Day One Staff (2020) Alexa and Amazon devices Covid-19 resources. [online] Available from: https://blog.aboutamazon.com/devices/alexaand-ama zon-devices-covid-19-resources?ots $=1 \&$ tag $=$ curbedcom 06- 20\&linkCode=w50 [Accessed 23 April 2020].

[19] Kapoor, A., Guha, S., Das, M.K., Goswami, K.C. and Yadav, R. (2020) Digital healthcare: The only solution for better healthcare during COVID-19 pandemic?. Indian Heart Journal.

[20] Wright, J.H. and Caudill, R., 2020. Remote treatment delivery in response to the COVID-19 pandemic. Psychotherapy and Psychosomatics, 89(3), p.1.

[21] Doshi, A., Platt, Y., Dressen, J.R., Mathews, B.K. and Siy, J.C., 2020. Keep calm and log on: telemedicine for COVID-19 pandemic response. J Hosp Med, 15(5), pp.302-304.

[22] Zenysis (2020). [online] Available from: https://www.zenysis.com [Accessed 23 April 2020].

[23] mHero (2020). [online] Available from: https://www.mhero.org [Accessed 23 April 2020].

[24] Zoom (2020). [online] Available from: https://zoom.us [Accessed 23 April 2020].

[25] Parez, S. (2020) Coronavirus-related Facebook support groups reach $4.5 \mathrm{M}$ in US as misinformation and conspiracies spread. Available from: https://techcrunch.com/2020/04/21/coronavirus-relate d

[26] Davis, A., Bersoff, E., E. Comer, E., "A strategy for comparing alternative software development life cycle models," (1988) IEEE Transactions on Software Engineering, vol. 14, no. 10, pp. 1453-1461.

[27] Beck, K. (2000) Extreme programming explained: embrace change. addison-wesley professional.

[28] Paulk, N., "Extreme programming from a CMM perspective" (2001) IEEE Software, vol. 18, no. 6, pp. 19-26. Available: 10.1109/52.965798.

[29] Flutter (2020). [online] Available from: https://flutter.dev [Accessed 15 April 2020].

[30] Nielsen, J. (1994) "Severity Ratings for Usability Problems: Article by Jakob Nielsen", Nielsen Norman Group. [Online]. Available: https://www.nngroup.com/articles / how-to-rate-the-se verity-of- usability-problems/. [Accessed: 06- Mar2019].

[31] ACORN || Union for the Community. (2020). ACORN Coronavirus Community Support. [online]Available from: https://acorntheunion.org.uk/corona/ [Accessed 15 Apr. 2020].

[32] England, N. (2020). NHS England "Temporary pause in recruitment to NHS Volunteer Responders. [online] England.nhs.uk. Available from: https://www.england.nhs.uk/participation/getinvolved/volunteering/nhs-volunteer-responders [Accessed 15 Apr. 2020].

[33] EUROPOL, (2020) Pandemic Profiteering. [online] EU: European Union Agency for Law Enforcement Cooperation, pp.1-13. Available from: https://www.europol.europa.eu/publications-

documents / pandemic-profiteering-how-criminals-explo it-covid-19- crisis [Accessed 15 April 2020]. 